\title{
Principal Component Analysis of Body Measurements of Yankassa Sheep in Anyigba, Kogi State, Nigeria
}

\author{
Adejoh Christiana Ojonegecha ${ }^{1}$, Musa Abdulraheem Arome ${ }^{1}$, Okoh Joseph Joseph ${ }^{2}$, \\ Okolo Freedom Atokolo ${ }^{3}$, Emmanuel Amanabo Theophilus ${ }^{4}$, Efienokwu Jude \\ ${ }^{1}$ Department of Animal Production, Kogi State University, Anyigba, Nigeria \\ ${ }^{2}$ Department of Animal Science, Federal University of Kashere, Gombe, Nigeria \\ ${ }^{3}$ Department of Animal Science, University of Ibadan, Ibadan, Nigeria \\ ${ }^{4}$ Department of Animal Science, University of Ilorin, Ilorin, Nigeria \\ ${ }^{5}$ Department of Science Laboratory Technology, Delta State Polytechnic, Ogwashi-Uku, Nigeria \\ Email address: \\ christy4god1982@gmail.com (A. C. Ojonegecha)
}

\section{To cite this article:}

Adejoh Christiana Ojonegecha, Musa Abdulraheem Arome, Okoh Joseph Joseph, Okolo Freedom Atokolo, Emmanuel Amanabo Theophilus, Efienokwu Jude. Principal Component Analysis of Body Measurements of Yankassa Sheep in Anyigba, Kogi State, Nigeria. Animal and Veterinary Sciences. Special Issue: Promoting Animal and Veterinary Science Research. Vol. 8, No. 2, 2020, pp. 45-50. doi: $10.11648 /$ j.avs.20200802.12

Received: November 7, 2019; Accepted: April 26, 2020; Published: June 3, 2020

\begin{abstract}
Yankasa sheep play a vital role in food security and the livelihood of smallholder farmers. This study aimed to evaluate the relationship amongst body measurements. A total of 126 extensively reared Yankasa rams, between $15.5-28.3$ months of age, were randomly selected for the study. Data on body measurements were collected and subjected to correlation, principal component (PC), and step-wise multiple regression analyses. We found that mean body measures ranged from $11.2 \mathrm{~cm}$ for scrotal circumference (SC) to $71.9 \mathrm{~cm}$ for chest girth (CG), and the coefficient of variation ranged from $10.7 \%$ for height at withers (HW) to $30.3 \%$ forBW. All body measures, except ear length, were significantly $(\mathrm{P}<0.01)$ associated with $\mathrm{BW}$. All body measures, except ear length, were significantly $(\mathrm{P}<0.01)$ associated with $\mathrm{BW}$. Of all body measures, $\mathrm{CG}$, rump width $(\mathrm{RW})$, and neck circumference (NC) were the most associated with BW, with correlation coefficients of $0.83,0.8$, and 0.79 , respectively, while neck length, ear width, and tail length were the least associated with correlation coefficients of $0.21,0.33$, and 0.46 . Three principal components from the factor analysis of body measurements explained about $64 \%$ of the total variance. Regression models using original morphometric traits as predictors explained up to $80 \%$ of the variation in body weight, while PC explained up to $75 \%$. This study shows that body measurements, such as CG, RW, and $\mathrm{NC}$, could serve as markers for BW in Yankasa sheep.
\end{abstract}

Keywords: Body Weight, Linear Body Measurements, Principal Component, Predictor, Yankasa Sheep

\section{Introduction}

Yankasa sheep are the most numerous and most widely distributed throughout the various ecological zones, particularly Guinea and Sudan Savanna vegetation belt of Nigeria, and constituted $60 \%$ of the total national flock [1]. Sheep are multifunctional animals that play a significant role in the economy and nutrition of landless, small and marginal poor farmers in most developing countries [2]. Sheep are sources of animal protein, and their production is almost entirely extensive with low input.
The main purpose of animal breeding practices is to improve the traits of economic value [3]. These traits have a close association with explanatory variables such as age, breed, and morphological characters. Genetic improvement of live weight is needed to increase meat yield from animals. Bodyweight is an important economic trait in the selection of animals for meat yield, and body measurements have been used in animals to estimate body weight $[4,5]$.

Multifactorial analyses of morphological traits have proven to be suitable in assessing the variation within a population [6]. Various multivariate techniques such as 
Principal Component Analysis (PCA), cluster analysis, multivariate regression analysis, discriminate statistics, canonical correlation analysis, and others have been applied for multivariate variable data analysis in the field of animal science and other related fields.

PCA is an interdependence technique whose primary purpose is to define the underlying structure among the variables in the analysis. Factor analysis provides the tools for analysing the structure of the interrelationships (correlations) among a large number of variables by defining sets of variables that are highly interrelated [7]. These groups of variables are highly inter-correlated and assumed to represent dimensions within the data.

PCA has been used as a tool in studying body shapes, in evolutionary studies, and in understanding the complex growth process among the body measurements of animals during the growth period [8]. The dearth of information on body measurements in Yankasa sheep using a multivariate approach in the study area necessitated this study. This study was, therefore, aimed at evaluating the relationship amongst body measurements and predicting body weight from linear body measurements in Yankasa sheep.

\section{Materials and Methods}

\subsection{Experimental Location and Site}

The experiment was carried out in Anyigba main market. Anyigba is located in the derived savanna of Nigeria on Latitude $7^{\circ} 30^{\prime} \mathrm{N}$ and Longitude $7^{\circ} 09^{\prime} \mathrm{E}$. The zone is characterized by $6-7$ months of annual rainfall ranging from $1400-1500 \mathrm{~mm}$ and daily temperature range of $25^{\circ} \mathrm{C}-35^{\circ} \mathrm{C}$ with the highest temperature in June - July [9].

\subsection{Experimental Animals}

A total of 126 randomly selected Yankasa ram between 15.5 - 28.3 months of age, as determined by dentition (presence of 4-6 permanent incisors) were used for the study. The interaction with the sellers revealed that the animals were extensively reared, with little or no provision for shelter at night.

\subsection{Traits Measured}

The body weight (BW) of each ram was measured in kilograms ( $\mathrm{kg})$ using a top-loading scale. Each ram was restrained in a natural position before taking measurements. Morphometric traits were determined in centimetre $(\mathrm{cm})$ using a measuring tape as outlined by Afolayan et al [1] as follows:

Body length (BL): the distance between the tip of the scapula to tail drop.

Height at withers (HW): the distance between the most cranial palpable spinous process and the ground.

Chest girth (CG): body circumference immediately behind the forelegs.

Neck length (NL): the distance between the base of the skull to the point of connection with the trunk.
Neck circumference (NC): the distance around the neck

Face length (FAL): the distance between the horn site to the lower lip.

Ear length (EL): the distance from the base to the tip of the ear.

Ear width (EW): the wideness of an ear.

Foreleg length (FL): the distance from the proximal extremity of the olecranon process to the mid-lateral point of the coronet.

Hind leg length (HL): the distance from the proximal extremity of the olecranon process to the mid-lateral point of the coronet.

Rump width (RW): the width between the hip bones (Tuber coxae).

Tail length (TL): the distance between the tail drop to tip of the tail.

Scrotal length (SL): the distance from the point of attachment to the tip of the scrotum.

Scrotal circumference (SC): the point of maximum dimension around the pendulous scrotum.

\subsection{Statistical Analysis}

Data collected were subjected to descriptive statistics of the Statistical Package for Social Sciences software [10]. Relationships among body measurements were determined using the correlation procedure of the same SPSS software. The principal component analysis was described [12] as a method for transforming the variables in a multivariate data set $X_{1}, X_{2} \cdots X_{n} \mathrm{X}$, into new variables, $Y_{1}, Y_{2} \cdots Y_{n} \mathrm{Y}$, which are uncorrelated with each other and account for decreasing proportions of the total variance of the original variables defined as:

$$
\begin{aligned}
& Y_{1}=a_{11} X_{1}+a_{12} X_{2}+\cdots+a_{1 n} X_{n} \\
& Y_{2}=a_{21} X_{1}+a_{22} X_{2}+\cdots+a_{2 n} X_{n} \\
& Y_{n}=a_{n 1} X_{1}+a_{n 2} X_{2}+\cdots+a_{n n} X_{n}
\end{aligned}
$$

with coefficients being chosen so that $Y_{1} \mathrm{Y}, Y_{2} \mathrm{Y}, \cdots, Y_{n} \mathrm{Y}$ account for decreasing proportions of the total variance of the original variables $X_{1}, X_{2}, \cdots, X_{n} \mathrm{X}$. Kaiser-Meyer-Olkin measures of sampling adequacy were computed to test the appropriateness of the factor analysis of the data. To enhance the interpretability of the principal components, we employed the varimax criterion of the orthogonal rotation method in the rotation of the factor matrix. Bodyweight prediction from linear body measurements and principal component factor scores using the stepwise multiple regression procedure was carried out using the following model:

$$
\begin{gathered}
B W=a+B_{i} X_{i}+\cdots+B_{n} X_{n} \\
B W=a+B_{i} P C_{i}+\cdots+B_{n} P C_{n}
\end{gathered}
$$

Where is the body weight, $a$ is the regression intercept, $B_{i} \mathrm{~B}$ is the $i^{t h}$ partial regression coefficient of the $i^{t h} \mathrm{i}$ linear body measurement, $X_{i} \mathrm{X}$ or the $i^{t h} \mathrm{i}$ principal component, $P C_{i}$. 


\section{Results and Discussion}

\subsection{Body Measurements in Yankasa Rams}

The mean \pm standard error, standard deviation, and coefficient of variation of body measurements in Yankasa rams are presented in Table 1 . The mean body measures ranged from $11.2 \mathrm{~cm}$ for $\mathrm{SC}$ to $71.9 \mathrm{~cm}$ for $\mathrm{CG}$, and the coefficient of variation ranged from $10.7 \%$ for $\mathrm{HW}$ to $30.3 \%$ for BW. The observed mean BL of $52.7 \mathrm{~cm}$ was higher than the value of $37.5 \mathrm{~cm}$ reported for the animals of the same age [11], but lower than the value of $59.4 \mathrm{~cm}$ reported for $0-14$ month Uda sheep and $70.9 \mathrm{~cm}$ for Yankasa sheep [8]. The observed mean BL in this study, however, agrees closely with the findings of hlTraore et al) [12] who reported ranges between 54.1 and $60.8 \mathrm{~cm}$ among Sudan, Sahel, and SudanSahel sheep types of Burkina-Faso.

HW and CG mean values, as indicated in Table 1, were higher but similar to the values of $62.1 \mathrm{~cm}$ and $21.0 \mathrm{~kg}$, respectively reported for Yankassa sheep [1] but lower 65.8, 76.2 and $84.6 \mathrm{cmin}$ other Yankassa. The mean FL observed was higher than the value of $47.7 \mathrm{~cm}$ reported for Yankasa and Uda breedsin a previous study [7] e while CG were similar (71.9) with that of the WAD (72.9). The observed RW of $16.3 \mathrm{~cm}$ was lower than the values of 18 and $21.5 \mathrm{~cm}$ reported by the same author [7]. FL values of 21.47 reported in the Uda [8] was comparable to the value of $20.88 \mathrm{~cm}$ obtained in this study.

The observed variations in morphometric measurements may be due to differences in environments where the studies were conducted. Large variation within certain measurements suggests the absence of selection or the parts respond more to the environment than others. In particular, CG measurements are usually affected by gut fill and are highly variable. Characteristically, FAL being a cephalic measurement, exhibits small variability because of its close association with cranial bone. The high variability shown by the standard deviation values associated with the measurements can also be a reflection of wide variation among actual ages of the used animal sample, which was not known.

Table 1. Means \pm standard error, standard deviation, and coefficient of variation of body measurements in Yankasa rams.

\begin{tabular}{llll}
\hline Traits & Mean & Standard deviation & CV (\%) \\
\hline Body length $(\mathrm{cm})$ & $52.71 \pm 0.63$ & 7 & 13.3 \\
Height at withers $(\mathrm{cm})$ & $66.34 \pm 0.64$ & 7.1 & 10.7 \\
Chest girth $(\mathrm{cm})$ & $71.91 \pm 0.7$ & 7.8 & 10.8 \\
Neck length $(\mathrm{cm})$ & $23.44 \pm 0.29$ & 3.3 & 14.0 \\
Neck circumference $(\mathrm{cm})$ & $33.1 \pm 0.63$ & 7.0 & 21.2 \\
Face length $(\mathrm{cm})$ & $20.88 \pm 0.19$ & 2.1 & 11.3 \\
Ear length $(\mathrm{cm})$ & $13.59 \pm 0.21$ & 2.4 & 17.6 \\
Ear width $(\mathrm{cm})$ & $6.07 \pm 0.08$ & 0.9 & 14.9 \\
Hindleg length $(\mathrm{cm})$ & $62.41 \pm 0.72$ & 8.1 & 12.9 \\
Scrotal length $(\mathrm{cm})$ & $17.33 \pm 0.26$ & 2.9 & 17.0 \\
Scrotal circumference $(\mathrm{cm})$ & $11.17 \pm 0.24$ & 2.6 & 23.6 \\
Tail length $(\mathrm{cm})$ & $39.9 \pm 0.49$ & 5.5 & 13.9 \\
Rump width $(\mathrm{cm})$ & $16.3 \pm 0.24$ & 2.7 & 16.3 \\
Foreleg length $(\mathrm{cm})$ & $61.47 \pm 0.62$ & 7.0 & 11.7 \\
Body weight $(\mathrm{kg})$ & $22.31 \pm 0.6$ & 6.8 & 30.3 \\
\hline
\end{tabular}

\subsection{Relationship Among Body Measurements}

Table 2 displays the correlation matrix for the body measurements obtained from Yankasa rams. All body measures, except EL, were significantly $(P<0.01)$ associated with BW. Of all body measures, CG, RW) and NC were the most associated with $\mathrm{BW}$, with correlation coefficients of $0.83,0.8$, and 0.79 , respectively, while NL, $\mathrm{EW}$, and TL were the least associated with correlation coefficients of $0.21,0.33$, and 0.46 respectively.

Body shapes measured objectively could improve selection for growth by enabling the breeder to recognize early maturing and late maturing animals of different sizes [5]. Further exploitation of body dimensions could be achieved by grouping them meaningfully. In such a case, their evolutionary significance is also studied. Positive and significant $(P<0.05)$ correlation among the measurements suggests high predictability among the measurements. The observed range of correlation was similar to those obtained in the Uda, WAD, and Yankasa [1, 8]. The observed high positive correlation coefficient between $\mathrm{BW}$ and $\mathrm{CG}$ compared to all other associations were similar and agreed with the findings of Afolayan et al; [1] who reported that of the linear body measurements, CG was the most related trait to BW with a correlation coefficient of 0.94. Similar observations have been reported between $\mathrm{CG}$ and $\mathrm{BW}$ in male and female Red Sokoto goats [13]. Variables such as height, length, and girth, which are directly related to the size and weight of animals, displayed moderate to very high positive correlations with one another and are comparable to the range of values recorded for goats in earlier studies [5, 14]. The positive correlations between BW and morphological traits obtained in the present study indicate that an increase in any one body measurement would result in a corresponding increase in live body weight. The strong relationship existing between $\mathrm{BW}$ and body measurements suggests that either or the combination of these morphological traits could be used to estimate live weight in sheep fairly well in the situation where weighbridges or scales are not available. The association may also be useful 
as a selection criterion since positive correlations of traits suggest that the traits may be under the same genetic influences.

Table 3 shows the Eigenvalues and share of the total variance, factor, and factor loadings after rotation of the linear body measurements of Yankasa rams. Kaiser-MeyerOlkin measure of sampling adequacy $(0.85$, which reveals the proportion of the variance in the body measurements caused by the underlying factor), Bartlett's test of sphericity $(P<0.01)$, communalities $(0.61-0.93$, the explained variance $)$ and the determinant $\left(1.11 \times 10^{-6} \mathrm{E}-06\right.$, obtained from the correlation matrix) permitted all body measurements into a reasonable factor analysis. After a high rotation $(>0.5)$ of the component matrix, three principal components were yielded by the factor solution, as presented in Table 3. The proportion of shared variance indicated by PC1, PC2, and PC3 accounted for 47.24\%, 9.02\%, and 7.21\% of the total loadings, respectively, with the proportions of Eigenvalues being 6.61, 1.26, and 1.01. All linear body measurements except for EL and NL were loaded on PC1, $\mathrm{EB}, \mathrm{EL}$, and NL were loaded on $\mathrm{PC} 2$, and only $\mathrm{NL}$ was loaded on PC3.

Table 2. Correlation matrix for the body measurement of Yankasa rams.

\begin{tabular}{|c|c|c|c|c|c|c|c|c|c|c|c|c|}
\hline Traits & BL & HW & CG & NL & $\mathrm{NC}$ & FAL & EL & EW & HL & TL & RW & FL \\
\hline HW & $0.59^{* *}$ & - & & & & & & & & & & \\
\hline $\mathrm{CG}$ & $0.66^{* *}$ & $0.672^{* *}$ & - & & & & & & & & & \\
\hline NL & $0.25^{* *}$ & $0.2^{*}$ & $0.28^{* *}$ & - & & & & & & & & \\
\hline $\mathrm{NC}$ & $0.65^{* *}$ & $0.64^{* *}$ & $0.75^{* *}$ & 0.17 & - & & & & & & & \\
\hline FAL & $0.43^{* *}$ & $0.53^{* *}$ & $0.45^{* *}$ & $0.31^{* *}$ & $0.5^{* *}$ & - & & & & & & \\
\hline EL & 0.16 & 0.07 & 0.09 & 0.17 & 0.03 & 0.133 & - & & & & & \\
\hline EW & $0.38^{* *}$ & $0.5^{* *}$ & $0.42^{* *}$ & 0.14 & $0.35^{* *}$ & $0.27^{* *}$ & $0.39^{* *}$ & - & & & & \\
\hline TL & $0.38^{* *}$ & $0.59^{* *}$ & $0.49^{* *}$ & $0.22^{*}$ & $0.45^{* *}$ & $0.47^{* *}$ & $0.20^{*}$ & $0.33^{* *}$ & $0.4^{* *}$ & - & & \\
\hline RW & $0.67^{* *}$ & $0.62^{* *}$ & $0.73^{* *}$ & 0.15 & $0.68^{* *}$ & $0.43^{* *}$ & 0.06 & $0.36^{* *}$ & $0.48^{* *}$ & $0.42^{* *}$ & - & \\
\hline FL & $0.58^{* *}$ & $0.72^{* *}$ & $0.65^{* *}$ & 0.08 & $0.6^{* *}$ & $0.43^{* *}$ & 0.12 & $0.41^{* *}$ & $0.5^{* *}$ & $0.46^{* *}$ & $0.58^{* *}$ & - \\
\hline BW & $0.68^{* *}$ & $0.65^{* *}$ & $0.83^{* *}$ & $0.21^{*}$ & $0.79^{* *}$ & $0.49^{* *}$ & -0.01 & $0.33^{* *}$ & $0.52^{* *}$ & $0.46^{* *}$ & $0.8^{* *}$ & $0.66^{* *}$ \\
\hline
\end{tabular}

*: Correlation is significant at the 0.05 level (2-tailed); **: Correlation is significant at the 0.01 level (2-tailed); BL: body length; HW: height at withers; CG: chest girth; NL: neck length; NC: neck circumference; FAL: face length; EL: ear length; EW: ear width; HL: Hindleg length: SL: scrotal length; SC: scrotal circumference; TL: tail length; RW: rump width; FL: Foreleg length; BW: body weight

The total variance of 63.47 accounted for by the derived PCs was lower than $78.7 \%$ in Uda sheep [7] but may be considered as a generalized size factor as in a similar investigation with cattle [15]. Name of author and reference to the publication Berge further reported that $75 \%$ of the generalized variance was explained by the factors. The first component variable loadings could be termed body size and were similar to what was observed in WAD goatand Uda sheep [13, 7], and mature Balami sheep [3]. The second and third component variables indicate more of defining characteristics for the animals. Two major underlying factors are responsible for the observed clusters [7]. These may be related to the different associations of each measurement with bone, environmental components, or the time taken to reach maturity. These in turn will be expected to change with time/age. More importantly, the elements present in each cluster probably have common genomic sites for their genetic control. In other words, pleiotropy is likely implicated.

Table 3. Eigenvalues and share of the total variance, factor and factor loadings after rotation of the body dimensions of Yankasa rams.

\begin{tabular}{llll}
\hline \multirow{2}{*}{ Traits } & \multicolumn{3}{l}{ Component } \\
\cline { 2 - 4 } & $\mathbf{1}$ & $\mathbf{2}$ & $\mathbf{3}$ \\
\hline Chest girth & 0.84 & -0.15 & 0.07 \\
Neck circumference & 0.83 & -0.24 & 0.02 \\
Height at withers & 0.82 & -0.09 & 0.01 \\
Body length & 0.80 & -0.08 & -0.02 \\
Rump width & 0.80 & -0.23 & -0.04 \\
Fore leg length & 0.78 & -0.14 & -0.16 \\
Scrotal length & 0.68 & 0.06 & -0.16 \\
Scrotal circumference & 0.67 & -0.01 & -0.15 \\
\hline
\end{tabular}

\begin{tabular}{|c|c|c|c|}
\hline \multirow{2}{*}{ Traits } & \multicolumn{3}{|c|}{ Component } \\
\hline & 1 & 2 & 3 \\
\hline Hind leg length & 0.66 & -0.02 & 0.02 \\
\hline Tail length & 0.66 & 0.17 & 0.11 \\
\hline Face length; & 0.65 & 0.10 & 0.36 \\
\hline Ear width & 0.56 & 0.44 & -0.33 \\
\hline Ear length & 0.23 & 0.84 & -0.28 \\
\hline Neck length & 0.30 & 0.41 & 0.77 \\
\hline Eigenvalues & 6.61 & 1.26 & 1.01 \\
\hline Percentage of total variance & 47.24 & 9.02 & 7.21 \\
\hline Cummulative (\%) & 47.24 & 56.26 & 63.46 \\
\hline
\end{tabular}

Table 4 presents the stepwise multiple regression of body weight on original body measurements and their principal component (PC) factor scores in Yankasa rams. Original body measurements as explanatory variables indicated the consistency of $\mathrm{CG}$ as an explanatory variable for body weight in Yankasa rams. Three prediction equations were obtained with high regression coefficient $\left(R^{2}\right)$ values of 0.68 , 0.77 , and 0.80 using $\mathrm{CG}, \mathrm{RW}$ and $\mathrm{NC}$ as predictors for BW. Using PCs as predictors, we obtained two equations with $\mathrm{R}^{2}$ values of 0.72 and $0.75 . R^{2}$ values increased with increasing numbers of variables included as predictors but not with great margins in both equation groups.

The significant occurrence of $\mathrm{CG}$ as a $\mathrm{BW}$ predictor among original body measurement variables agrees with the previous findings [1] that the CG accounted for close to $90 \%$ of the body weight in this study. It also in agreement with the previous findings in the WAD and Red Sokoto goats [13], where CG was found to be the most efficient in predicting $\mathrm{BW}$. The result of the multiple regression analyses indicated 
that the addition of other measurements to $C G$ would result in significant improvements in prediction accuracy even though the extra gain was small, as revealed by the marginal increase in $\mathrm{R}^{2}$. However, under field conditions, $\mathrm{BW}$ estimation using $\mathrm{CG}$ alone would be preferable to combinations with other measurements because of the difficulty of the proper animal restraint during measurement. Consequently, this reduces the practical usefulness of using other body measurements in conjunction with CG [15]. The use of $\mathrm{CG}$ as the most reliable variable to predict $\mathrm{BW}$ under field conditions has also been recommended in previous studies [16, 18]. The importance of $\mathrm{CG}$ in $\mathrm{BW}$ estimation could be as a result of the fact that muscle, some fat along with bone structure contribute to its formation. However, the use of original body measurement should be treated with caution since multi-collinearity is associated with unstable estimates of regression coefficients [17], rendering the estimation of the unique effects of the predictors unreliable. This justifies the use of principal component factor scores for prediction. These factors are orthogonal to each other and are more reliable in BW estimation. PC1 accounted for approximately $72 \%$ of the variation in $\mathrm{BW}$, and the combination of $\mathrm{PC} 1$ and $\mathrm{PC} 2$ accounted for $75 \%$, suggesting that $\mathrm{PC} 1$ indicates overall body size and may be sufficient for BW prediction. PCA has been used to predict carcass and weaning weights in small ruminants [18].

Table 4. Stepwise multiple regression of body weight on original body measurements andtheir principal component (PC) factor scores in Yankasa rams.

\begin{tabular}{llll}
\hline Variables & Model & SE & $\mathbf{R}^{2}$ \\
\hline \multicolumn{2}{l}{ Original body measurements as explanatory variables } \\
CG & $\mathrm{BW}=-29.25+0.72 \mathrm{CG}$ & 3.8 & 0.68 \\
$\mathrm{CG}$ and RW & $\mathrm{BW}=-27.36+0.45 \mathrm{CG}+1.08 \mathrm{RW}$ & 3.3 & 0.77 \\
$\mathrm{CG}, \mathrm{RW}$, and NC & $\mathrm{BW}=-23.46+0.31 \mathrm{CG}+0.89 \mathrm{RW}+0.27 \mathrm{NC}$ & 3 & 0.8 \\
Orthogonal traits as independent variables & & \\
PC 1 & $\mathrm{BW}=22.31+5.73 \mathrm{PC} 1$ & 3.6 & 0.72 \\
PC 2 & $\mathrm{BW}=22.31+6.1 \mathrm{PC} 1-1.34 \mathrm{PC} 2$ & 3.4 & 0.75 \\
\hline
\end{tabular}

CG: chest girth; RW: rump width; NC: neck circumference; BW: body weight; PC: principal component; SE: standard error; R: regression coefficient

\section{Conclusion and Recommendation}

\subsection{Conclusion}

This study revealed through Pearson correlation coefficients that great and predictive degree of relationship existed amongst body measurements in Yankasa Sheep, and the highest singular pair was the association between BW and CG. We found $\mathrm{CG}$ and $\mathrm{PC} 1$ were the major predictors of $\mathrm{BW}$ when original body measurements and principal components, respectively, were used as predictors in Yankasa Sh.

\subsection{Recommendations}

It is recommended that similar studies using ewes at different age groups be embarked upon to verify the findings in this study or to shed more light on the morphostructure of the Yankasa breed.

\section{References}

[1] Afolayan, R. A., Adeyinka, I. A. and Lakpini, C. A. M. (2006). The estimation of live weight from body measurements in Yankasa sheep. Czech Journal of Animal Science, 5 (8): 343348 .

[2] Muhammad, K. Y., Birnin-Tsaba, N. I., Ibrahim, R., Yerima, U. A. and Tanko, S. D. (2006). Coat Colour Dilution in Sokoto Red Goats in Sokoto. A mini project report submitted in partial fulfillment of the requirement for ANI 503 (Applied Animal Breeding). Department of Animal Science, Faculty of Agriculture, Usmanu Danfodiyo University, Sokoto. (Unpublished).

[3] Mendes, M., Karabayir, A. and Pala, A. (2005). Path analysis of the relationship between various body measures and live weight of American Bronze turkeys under three different lighting programs. TarimBilimleriDergisi, 11: 184-188.

[4] Topal, M. and Macit, M. (2004). Prediction of body weight and body measurements in Morkaraman sheep. Journal of Applied Animal Research, 25: 97-100.

[5] Yakubu, A. (2009). Fixing collinearity in the estimation of body weight from morph-biometrical traits of West African Dwarf goats. Trakia Journal of Science, 7: 61-66.

[6] Yakubu, A. and Ibrahim, I. A. (2011). Multivariate analysis of morphostructural characteristics in Nigerian indigenous sheep. Italian Journal of Animal Science, 10: 83-86.

[7] Salako, A. E. (2006). Application of morphological indices in the assessment of type and function in sheep. International Journal of Morphology, 24 (1): 13-18.

[8] Leng, J., Zhu, R., Zhao, G., Yang, Q. and Mao, H. (2010). Quantitative and qualitative body traits of Longling Yellow goats in China. Agricultural Sciences in China, 9: 408-415.

[9] Okoh, J. J. Ocholi, R. E. and Igomu, M. N. (2013) Phenotypic characterization of indigenous breeds of sheep in selected states of derived guinea savannah Agro-ecological Zone of NigeriaSociety for Agriculture, Business and Technology. ATBU, Bauchi Vol 2 No. 3: 173- 180. ISSN 2007-0807

[10] SPSS, (2011). Statistical Package for Social Sciences. SPSS Inc., 444 Michigan Avenue, Chicago, IL60611.

[11] Everitt, B. S., Landau, S. and Leese, M., (2001). Cluster analysis. $4^{\text {th }}$ edn., (Arnold Publisher, London).

[12] Traoré, A., Tamboura, H. H., Kaboré, A., Royo, L. J., Fernández, I., Álvarez, I., Sangaré, M., Bouchel, D., Poivey, J. P., Francois, D., Toguyeni, A., Sawadogo, L. and Goyache, F. (2008). Multivariate characterization of morphological traits in Burkina Faso sheep. Small Ruminant Research, 80: 62-67.

[13] Okpeku, M., Yakubu, A., Peters, S. O., Ozoje, M. O., Ikeobi, C. O. N., Adebambo, A. O. and Imumorin, I. G. (2011). Application of multivariate principal component analysis to morphological characterization of indigenous goats in Southern Nigeria. ActaAgriculturaeSlovenica, 98 (2): 101109.

[14] Sowande, O. S., Oyewale, B. F. and Iyasere, O. S. (2010). Age and sex dependent regression models for predicting the live weight of West African Dwarf goat from body measurements. Tropical Animal Health Production, 42: 969-975. 
[15] Berge, S. (1997). On the estimation of weight and increase in weight by means of the chest girth in Norwegian red cattle at the Agricultural University Norway in the years 1972 and 1974. Acta Agriculture Scandinavia, 27: 65-66.

[16] Badi, A. M. I., Fissehaye, N. and Rattan, P. J. S. (2002). Estimation of live body weight in Eritrean goat from heart girth and height at withers. Indian Journal of Animal Science, 72: 893-895.

[17] Malau-Aduli, A. E. O., Aziz, M. A., Kojina, T., Niibayashi, T.,
Oshima, K. and Komatsu, M. (2004). Fixing collinearity instability using principal component and ridge regression analyses in the relationship between body measurements and body weight in Japanese Black cattle. Journal of Animal and Veterinary Advances, 3: 856-863.

[18] Eyduran, E., Karakus, K., Karakus, S. and Cengiz, F. (2009). Usage of factor scores for determining relationships among body weight and somebody measurements. Bulgarian Journal of Agricultural Science, 15: 373-377. 